\title{
SUSTENTABILIDADE E INDUSTRIALIZAÇÃO: OS IMPACTOS DA PRÉ-FABRICAÇÃO NO CONSUMO DE MADEIRA
}

\author{
SUSTAINABILITY AND INDUSTRIALIZATION: \\ THE IMPACTS OF PREFABRICATION ON WOOD CONSUMPTION
}

\section{Tamyres Blenke Narloch, Ma. (UFSC) Lisiane Ilha Librelotto, Dra. (UFSC)}

\author{
Palavras chave \\ Sustentabilidade; Industrialização; Madeira
}

\author{
Key words \\ Sustainability; Industrialization; Wood
}

\section{RESUMO}

A busca pela sustentabilidade tem sido um desafio para diversas áreas, na construção civil com a imensa geração de resíduos, consumo energético e de matéria prima não tem sido diferente. Esta pesquisa tem por objetivo analisar aspectos que contribuem para a o projeto de edificações mais sustentáveis na implantação da pré-fabricação como uma etapa para a industrialização. A pesquisa utilizou dados de planilhas orçamentárias de dois empreendimentos em alvenaria estrutural e de entrevista realizada com o coordenador de pesquisa e desenvolvimento de uma construtora do norte do estado de Santa Catarina. Foi feita uma análise comparativa do consumo de madeira, sendo que uma das obras foi executada com concreto moldado in loco e a outra teve os pavimentos térreo e ático (não repetitivos) em sistema misto (moldado in loco e pré-fabricado) e os pavimentos tipo (repetitivos) pré-fabricados. Nos pavimentos mistos a redução no consumo de madeira foi de $61 \%$ e nos pavimentos pré-fabricados a redução foi de $100 \%$. Ao fim da pesquisa foi possível concluir que, apesar da pré-fabricação não permitir flexibilidade nas plantas, ela melhorou as condições de trabalho dos operários, reduziu consumo de madeira e de seus resíduos.

\section{ABSTRACT}

The search for sustainability has been a challenge for several areas, in the construction industry with the immense generation of waste, energy consumption and raw material has not been different. This research aims to analyze aspects that contribute to the design of more sustainable buildings in the implantation of prefabrication as a stage for industrialization. The research used data from budget worksheets of two projects in structural masonry and an interview with the research and development coordinator of a construction company in the northern part of the state of Santa Catarina. A comparative analysis of the consumption of wood was carried out, one of which was executed with cast-in-place concrete and the other had the ground and attic floors (non-repetitive) in mixed system (cast-in-place and prefabricated) and pavements prefabricated (repetitive) types. In the mixed pavements the reduction in wood consumption was $61 \%$ and in the prefabricated floors the reduction was of $100 \%$. At the end of the research it was possible to conclude that, although the prefabrication did not allow flexibility in the plants, it improved the working conditions of the workers, reduced the consumption of wood and its residues. 


\section{INTRODUÇÃO}

Segundo Araújo (2008) as discussões sobre sustentabilidade iniciaram na década de $70 \mathrm{com}$ a crise do petróleo, sendo o primeiro evento internacional sobre construção sustentável na década de 90 . Desde então, a sustentabilidade vem se modificando conforme novos estudos e necessidades vão surgindo.

Para um desenvolvimento sustentável deve-se atender as necessidades do presente sem comprometer as necessidades das gerações futuras (BRUNDTLAND et al., 1987). Por si só, este conceito já apresenta falhas no sentido de que não estarem sendo atendidas de forma satisfatória e igualitária as necessidades desta geração. Pensar em redução dos impactos, dos resíduos, do consumo de água, do despejo de efluentes, do consumo de energia nas edificações, ao mesmo tempo em que se promove equidade econômica e social é um desafio para a indústria da construção civil.

As edificações mais sustentáveis devem consumir recursos de forma racional, utilizar materiais ecologicamente corretos e impactar minimamente no ambiente no qual se inserem, isso tudo desde sua concepção (LAMBERTS et al., 2007).

Por isso, é necessário considerar desde a transformação que o ambiente natural está sofrendo até que se torne ambiente construído, buscando consumir menos recursos e energia, gerando menos poluição, reciclando e reutilizando materiais, dentro da capacidade de suporte do planeta. Segundo o relatório de 2016 da World Wide Fund for Nature (WWF) esta capacidade já foi ultrapassa$\mathrm{da}$, considerando uma população de mais de 7,2 bilhões de habitantes e os impactos já causados (SATTLER, 2017).

Considerando estes aspectos, o objetivo desta pesquisa foi realizar uma análise das relações entre sustentabilidade e industrialização, através das quantidades de madeira utilizadas em processos de moldagem in loco de estruturas de concreto e da pré-fabricação de componentes. Foi aplicada em uma construtora do norte do estado de Santa Catarina, onde também foram analisados qualitativamente aspectos inerentes aos processos.

Segundo Franco (1992) a industrialização traz vantagens no que tange a integração de processos e projetos, planejamento para a produção, racionalização, utilização de pré-fabricados, proteção da produção (bens físicos e materiais) em relação ao clima, além de menos desperdícios de materiais, por exemplo.

A construção civil no Brasil, é hoje, em grande parte, uma atividade artesanal, exigindo assim uma mão de obra extremamente especializada. No entanto também é caracterizada por empregar operários sem qualificação.
Esse contrassenso resulta em desperdícios de materiais e mão de obra, atraso nos prazos e altíssimo custo, ainda que os salários sejam baixos. A formação de mão de obra especializada acaba por ser demorada e cara, por isso a racionalização, mecanização e produção em massa se apresenta como uma forma de baratear custos e empregar trabalhadores sem qualificação. A pré-fabricação é uma das etapas para a industrialização por exigir organização e produção em série para se tornar viável (BRUNA, 2013).

\section{REVISÃO}

\subsection{Sustentabilidade e o consumo de madeira na construção civil}

A sustentabilidade deve ser tratada não como um objetivo, mas como um processo. Por isso deve partir de um projeto conjunto entre os interventores como: proprietários, arquitetos, engenheiros, consultores, fabricantes de materiais, operários de obra e os ocupantes da edificação, por exemplo (PRIZIBELA; OLIVEIRA, 2016). Segundo os autores, a ferramenta mais utilizada para uma concepção de projeto mais sustentável são as leis e normas, principalmente devido à sua obrigatoriedade legal.

Além de leis e normas, existem também várias certificações, etiquetas e selos como: AQUA (Haute Qualité Environnementale - HQE na França), LEED (Leadership in Energy and Environmental Design), PBE Edifica (Programa Brasileiro de Etiquetagem) e Selo Casa Azul, por exemplo. Algumas destas certificações possuem requisitos oriundos das próprias legislações (BEZERRA; OLIVEIRA, 2016).

A união dos requisitos legais com os critérios estabelecidos nas certificações permite aos pesquisadores um vislumbre da amplitude do conceito de sustentabilidade e quais os aspectos mais considerados em sua determinação. Sem dúvida o uso racional dos recursos naturais está presente na maioria dos determinantes legais.

$\mathrm{O}$ uso racional dos recursos naturais abrangendo a integração e dependência entre questões socioculturais, políticas e estéticas, por exemplo, é que originam a construção sustentável. A forma como são projetadas, construídas e utilizadas as edificações, influencia diretamente no consumo dos recursos e no atendimento das necessidades da população. Por isso deve-se escoIher o processo construtivo que gere menos impactos, sendo este um momento decisivo para a sustentabilidade futura da edificação (CARVALHO, 2009).

Cerca de $50 \%$ de todos os recursos extraídos da crosta terrestre são absorvidos pelo ambiente construído, através da indústria da construção, consumindo ainda entre 40 e 
50\% da energia utilizada (CIB \&amp; UNEP-IETC, 2002).

Araújo (2003 apud PRIZIBELA; OLIVEIRA, 2016) estima que as edificações sejam responsáveis por $30 \%$ das emissões de gás carbônico e de $40 \%$ dos resíduos gerados pelo homem na União Europeia. No Brasil, cerca de 70\% da madeira utilizada não provém de manejo florestal adequado.

Os dados da Tabela 1 levantados pelo Serviço Florestal Brasileiro mostram uma visão das florestas brasileiras, tanto naturais quanto plantadas (SFB, 2009; 2010; 2013). consumo de materiais de regularização(RUTHES, 2016).

Ao fim da pesquisa o autor conclui que a implementação de um processo industrializado influenciou em quase todos os departamentos da construtora. Após seu ciclo de desenvolvimento, as etapas de orçamento e planejamento tiveram seu tempo reduzido em aproximadamente $40 \%$. Houveram ainda outros ganhos relacionados a racionalização construtiva, mas que não dependem diretamente de altos investimentos em industrialização, podendo ser aplicáveis em outras obras. No entanto um

Tabela 1: Estatísticas do Serviço Florestal Brasileiro.

\begin{tabular}{|l|c|c|c|}
\hline \multicolumn{1}{|c|}{$\begin{array}{c}\text { Principais estatísticas } \\
\text { nacionais }\end{array}$} & $\mathbf{2 0 0 8}$ & $\mathbf{3 0 0 9}$ & $\mathbf{2 0 1 1 / 2 0 1 2}$ \\
\cline { 2 - 4 } & $61,5 \%$ & $60,7 \%$ & $54,4 \%$ \\
\hline Área florestal / Área total do pais & 2,85 ha & 2,70 ha & 2,38 ha \\
\hline Área florestal / Habitante & 517 milhōes de ha & 509,8 milhōes de ha & 456 milhōes de ha \\
\hline Área de florestas naturais & 6,6 milhōes de ha & 6,8 milhōes de ha & 7,2 milhōes de ha \\
\hline Área de florestas plantadas
\end{tabular}

Fonte: adaptado de SFB (2009; 2010; 2013).

\subsection{Industrialização de processo na construtora através da pré- fabricação}

A industrialização é muitas vezes vista como uma forma de diminuir a quantidade de empregos para a grande massa de mão de obra não qualificada. No entanto a baixa qualidade do produto final, os altos custos de produção, a falta de qualidade no ambiente de trabalho dos operários e o grande desperdício de materiais das construções tradicionais, não justifica o status quo tecnológico. A forma mais racional de resolver estes embates, aumentar produtividade e ainda empregar mão de obra não qualificada é com a industrialização (BRUNA, 2013).

Ruthes (2016) fez uma pesquisa na mesma construtora objeto deste estudo, onde avaliou "os impactos gerados no desenvolvimento de um processo construtivo industrializado em alvenaria estrutural\&quot;. A empresa possui uma central de pré-fabricação implantada em 2014 para lajes, vigas, escadas, sacadas e outros elementos menores. A linha de produção segue um fluxo circular percorrendo as etapas de aplicação de desmoldante, armação, elétrica, colocação de dispositivos de içamento, concretagem, vibração, cura e desforma. A central está localizada próxima a sede administrativa da construtora, de onde os elementos pré-fabricados são transportados para as obras.

Antes da utilização de lajes pré-fabricadas a empresa as fazia moldadas in loco (Figura 1). A Figura 2 mostra as diferenças entre os primeiros e últimos pavimentos, devido à reutilização das formas plastificadas. As ondulações nas lajes dos últimos pavimentos chegam a $3 \mathrm{~cm}$, aumentando fator negativo é a falta de flexibilidade do projeto, devido à pré-fabricação de elementos ser padronizada.

Figura 01: Escoramento da laje moldada no local (a) e formas de madeira posicionadas para concretagem (b).

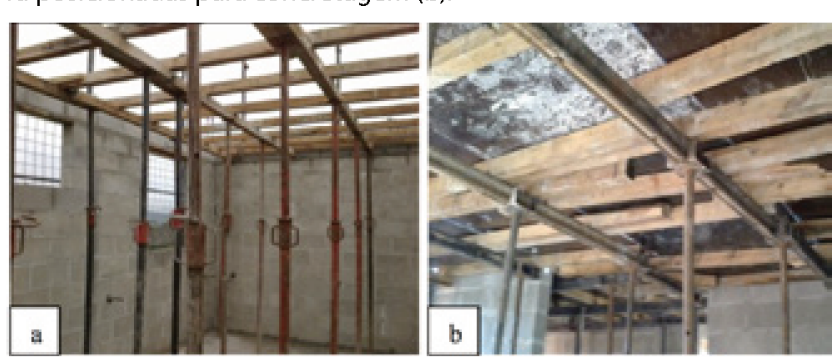

Fonte: cedida pela construtora (2014).

Figura 02: Acabamento da laje nos pavimentos inferiores (a) e acabamentos das lajes nos pavimentos superiores (b)

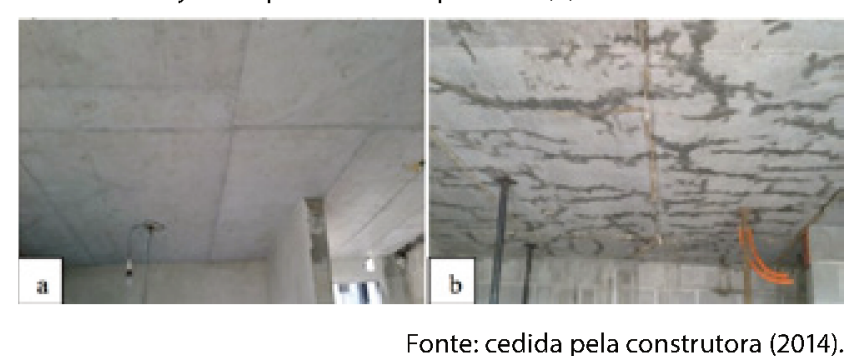

\section{PROCEDIMENTOS METODOLÓGICOS}

\subsection{Etapas e estrutura do trabalho}

A pesquisa foi feita em algumas etapas, iniciando com a pesquisa bibliográfica apresentada no capítulo 2 , onde 
foram apresentadas informações importantes que embasam a relação entre sustentabilidade e industrialização.

Em seguida foram obtidos e compilados os dados fornecidos pela construtora, apresentados no item 4, do qual fazem parte as análises das planilhas e a entrevista com o coordenador de pesquisa e desenvolvimento da construtora. Para a entrevista as autoras solicitaram ao coordenador que comentasse de forma livre (sem questionários) o processo de alteração de concreto moldado in loco para a pré-fabricação.

Com a revisão e os resultados foi possivel fazer uma análise e apresentar no item 5 as considerações finais.

\subsection{Método da pesquisa}

Conforme Yin (2001) e Severino (2007) a pesquisa pode ser caracterizada como quantitativa, por analisar os consumos de madeira nas obras com lajes pré-fabricadas e nas com lajes moldadas in loco. Qualitativa, por analisar aspectos subjetivos relacionados aos dois processos. Documental, pois estes consumos foram analisados através de relatórios de orçamento das obras pelo sistema SAP. Exploratória, devido a delimitação do campo de trabalho.

\section{RESULTADOS}

Para o estudo a construtora forneceu os relatórios obtidos do sistema SAP, com as planilhas orçamentárias de empreendimentos executados com elementos moldados in loco e os mesmos elementos (lajes, vigas, escada, vergas e contravergas) pré-fabricados.

Para complementar a análise, foi feita entrevista com o coordenador de pesquisa e desenvolvimento, que participou de todo o processo de industrialização desta etapa.

\subsection{Caracterização da empresa e dos empreendimentos}

A empresa em estudo está localizada no norte do estado de Santa Catarina, foi fundada em 2006 e possui cerca de 200 funcionários diretos. Desde 2010 possui certificação nível A no PBQP-H (Programa Brasileiro da Qualidade e Produtividade do Habitat) e ISO 9001 (estabelece requisitos para o Sistema de Gestão da Qualidade de uma organização). Já soma cerca de 4500 apartamentos entregues e em construção, em basicamente dois sistemas construtivos: estrutura de concreto moldada in loco com fechamento em blocos cerâmicos e alvenaria estrutural em blocos de concreto. O segundo sistema é foco deste estudo onde, a partir de 2014, foi implantado o processo de pré-fabricação de lajes, vigas, escada e pequenos elementos nos pavimentos que se repetem.

Foram selecionados dois empreendimentos ( $F$ e $G$ ), ambos em alvenaria estrutural para esta pesquisa. Eles possuem 2 torres de apartamentos com um total de 198 unidades no empreendimento $\mathrm{Fe} 190$ no $\mathrm{G}$. Além de torre de garagens e área comum, como área de festas, guarita e lixeira, por exemplo. O layout dos pavimentos tipo dos 2 empreendimentos é igual, exceto por uma diferença de $31 \mathrm{~m} 2$, decorrente de um aumento exigido pela prefeitura no empreendimento F. Por ter a planta alterada o empreendimento $F$ foi todo feito em concreto moldado in loco, enquanto o empreendimento $G$ teve os pavimentos tipo e cobertura pré-fabricados, já os pavimentos térreo e ático foram um sistema misto dos dois processos. A Tabela 2 lista as áreas destes empreendimentos, a Figura 3 mostra as formas do processo moldado in loco, enquanto as figuras 4 e 5 mostram os pré-fabricados.

\subsection{Consumo de madeira nas obras}

Em função da extensão das planilhas com os quantitativos (cerca de 22 mil linhas cada), aqui serão apresentados alguns somatórios do consumo de madeira de cada obra. Nesses consumos estão inclusos os materiais referentes a execução da obra como: formas, escoramentos,

Tabela 02: Área construída dos empreendimentos F e G.

\begin{tabular}{|c|c|c|}
\hline \multirow{2}{*}{ Área construida (m2) } & \multicolumn{2}{|c|}{ Empreendimento } \\
\cline { 2 - 3 } & $\mathrm{F}$ & $\mathbf{G}$ \\
\hline Áreas comuns e garagens & 4828,46 & 4689,65 \\
\hline $\begin{array}{c}\text { Primeiro pavimento e ático das torres de } \\
\text { apartamentos }\end{array}$ & 1513,70 & 1452,10 \\
\hline $\begin{array}{c}\text { Pavimento tipo e cobertura das torres de } \\
\text { apartamentos }\end{array}$ & 14073,90 & 12734,70 \\
\hline Total & 20416,06 & 18876,45 \\
\hline
\end{tabular}


gabaritos, materiais para instalações de segurança (guarda-corpo, bandejão) e instalações provisórias. Não foram considerados materiais inerentes ao produto final como: esquadrias, mobília, estrutura das coberturas e deck de madeira, por exemplo.

Figura 03: Formas para concretagem do in loco.

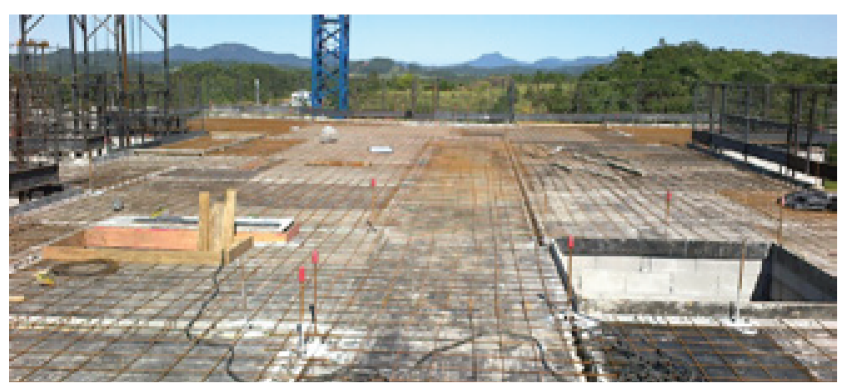

Fonte: cedida pela construtora (2018).

Figura 04: Formas para pré-fabricação.

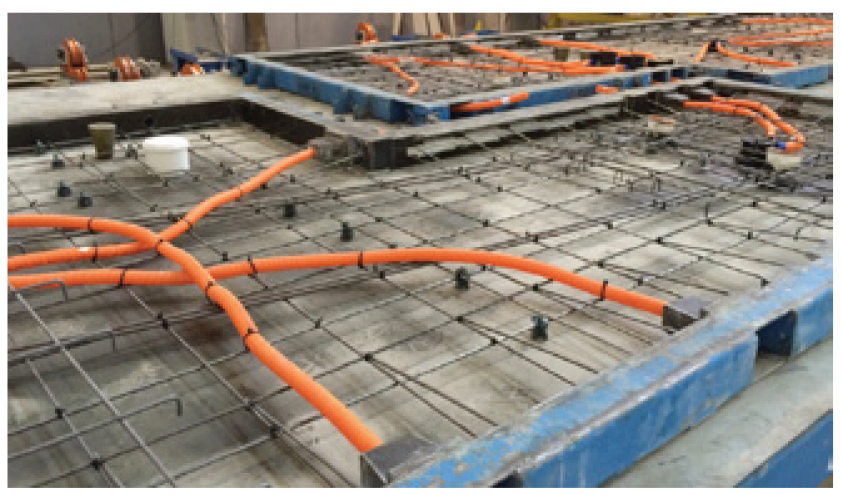

Fonte: Cedida pela construtora (2018).

Figura 05: Montagem das lages pré-fabricadas.

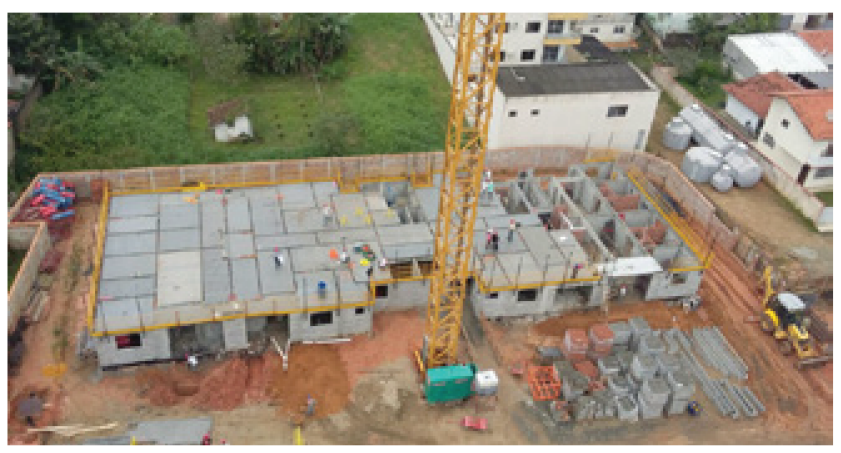

Fonte: cedida pela construtora (2018).

Para se ter uma relação proporcional do consumo de madeira, cada dado foi dividido pelas áreas apresentadas na Tabela 3 . e já quantificadas na Tabela 2. Os resultados, bem como a diferença percentual do consumo de madeira do empreendimento $G$ em relação ao $\mathrm{F}$ foram apresentados na Tabela 4.

Alguns itens precisariam de uma análise mais ampla para que fosse possível concluir o motivo da diferença de consumo da madeira, como:

a) Estruturas e instalações das áreas comuns e garagens: por terem sido executados com concreto moldado in loco nos dois empreendimentos, a diferença pode ser principalmente a diferenças no projeto arquitetônico das áreas comuns (salão de festas, guarita e lixeira, por exemplo) e das garagens

b) Instalações de segurança: como o projeto arquitetônico das áreas comuns dos empreendimentos é diferente, o projeto de proteção coletiva também é outro

c) Instalações provisórias: ambientes como almoxarifado, escritório, banheiros e refeitório foram feitos em madeira nas duas obras, mas a forma e área do terreno, quantidade de trabalhadores e legislação de cada cidade, por exemplo, podem influenciar diretamente nas suas proporções;

d) Fundações, baldrame e acessos das torres de apartamentos: as fundações não são padronizadas por dependerem do tipo de solo, mesmo em projetos exatamente iguais (com as mesmas cargas nos blocos), além das diferenças entre os níveis que alteram a forma dos acessos das áreas comuns para as torres.

Já nos outros dois itens, as diferenças devido à pré-fabricação são mensuráveis:

a) Pavimento térreo e ático das torres de apartamentos: como estes pavimentos não se repetem em uma mesma torre, alguns elementos não viabilizaram através da pré-fabricação, já outros que também seriam utilizados no pavimento tipo foram pré-fabricados, esta solução mista entre pré-fabricados e moldados in loco gerou a redução de $61 \%$ no consumo de madeira;

b) Pavimento tipo e cobertura das torres de apartamentos: o pavimento cobertura destes empreendimentos é meio pavimento tipo, assim também teve a repetitividade como viabilizadora para a pré-fabricação, nestes pavimentos o consumo de madeira é zero, pois as lajes pré-fabricadas são transportadas para cada obra, içadas e apoiadas sobre escoras e perfis metálicos, até a cura da concretagem das costuras.

\subsection{Entrevista}

A entrevista relatada a seguir foi feita no dia $11 \mathrm{de} \mathrm{ja-}$ neiro de 2018 com o coordenador de pesquisa e desenvolvimento da construtora em estudo.

No processo com formas de madeira plastificadas, o ciclo de concretagem da laje durava 14 dias. Com o processo de lajes pré-fabricadas com formas metálicas houve 
Tabela 03: Consumos analisados e suas respectivas áreas.

\begin{tabular}{|c|c|}
\hline Consumo de madeira & Área considerada \\
\hline $\begin{array}{c}\text { Estruturas e instalaçōes das áreas comuns e } \\
\text { garagens }\end{array}$ & Áreas comuns e garagens \\
\hline Instalaçōes de segurança & Área construída total \\
\hline Instalaçōes provisórias & Área construída total \\
\hline $\begin{array}{c}\text { Fundaçōes, baldrame e acessos das torres de } \\
\text { apartamentos }\end{array}$ & Pvto térreo das torres de apartamentos \\
\hline Pavimento térreo e ático das torres de apartamentos & Pvto térreo e ático das torres de aptos \\
\hline $\begin{array}{c}\text { Pavimento tipo e cobertura das torres de } \\
\text { apartamentos }\end{array}$ & $\begin{array}{c}\text { Pvto tipo e cobertura das torres de } \\
\text { aptos }\end{array}$ \\
\hline Total & Área construida total \\
\hline
\end{tabular}

Fonte: Autoras (2018).

Tabela 03: Consumos analisados e suas respectivas áreas.

\begin{tabular}{|c|c|c|c|c|c|}
\hline \multirow[t]{2}{*}{ Tarefa } & \multicolumn{2}{|c|}{$\begin{array}{l}\text { Consumo de } \\
\text { madeira (m3) }\end{array}$} & \multicolumn{2}{|c|}{$\begin{array}{c}\text { Consumo/Área } \\
(\mathrm{m} 3 / \mathrm{m} 2)\end{array}$} & \multirow{2}{*}{$\begin{array}{l}\text { Diferença no consumo } \\
\text { de } G \text { em relação a } F\end{array}$} \\
\hline & $\mathbf{F}$ & G & $\mathbf{F}$ & G & \\
\hline $\begin{array}{l}\text { Estruturas e instalaçōes das } \\
\text { áreas comuns e garagens }\end{array}$ & 205,6 & 188,0 & 0,0426 & 0,0401 & $-5,87 \%$ \\
\hline Instalaçōes de segurança & 41,5 & 32,2 & 0,0020 & 0,0017 & $-16,19 \%$ \\
\hline Instalaçōes provisórias & 47,8 & 54,9 & 0,0023 & 0,0029 & $24,19 \%$ \\
\hline $\begin{array}{c}\text { Fundaçōes, baldrame e } \\
\text { acessos das torres de } \\
\text { apartamentos }\end{array}$ & 119,2 & 72,8 & 0,0910 & 0,0583 & $-35,94 \%$ \\
\hline $\begin{array}{l}\text { Pavimento térreo e ático das } \\
\text { torres de apartamentos }\end{array}$ & 60,8 & 22,6 & 0,0402 & 0,0155 & $-61,30 \%$ \\
\hline $\begin{array}{l}\text { Pavimento tipo e cobertura } \\
\text { das torres de apartamentos }\end{array}$ & 57,6 & 0,0 & 0,0041 & 0,0000 & $-100,00 \%$ \\
\hline Total & 532,5 & 370,4 & 0,0261 & 0,0196 & $-24,77 \%$ \\
\hline
\end{tabular}

uma fase de aprendizado no início da implantação desta inovação, por isso na primeira obra o ciclo durou 30 dias, devido a ajustes, treinamentos e logística, por exemplo. No entanto, a partir da segunda obra, o ciclo com lajes pré-fabricadas já passou para 6 dias.

Antes da utilização de pré-fabricados a obra era planejada para durar 24 meses, mas comumente atrasava e era entregue em 30 meses. Hoje facilmente é terminada em 18 meses e em alguns casos já foi possível entregar em 15. Pode-se dizer que o sistema de lajes pré-fabricadas está chegando a um patamar de redução de $50 \%$ do tempo de execução de uma obra.

Além disso, a implantação da fábrica para estas lajes, a necessidade de um planejamento antecipado de logística, projetos bem detalhados e mão de obra capacitada, permitiu a industrialização de várias outras etapas como: elétrica, hidráulica, esgoto, vergas, contravergas e escada.

A maior dificuldade encontrada foi a mão de obra no canteiro, que não conhecia este tipo de sistema, seguida da mão de obra da fábrica. De um total de 20 postos de trabalho, passaram pela empresa 60 trabalhadores. Isto mostra que houveram 2 trocas de pessoal até que se conseguisse implementar o sistema de forma adequada.

Em relação ao projeto foram citados dois grandes embates, tempo e qualidade de projeto. Devido ao tempo de aprovação e licenciamento (que em algumas cidades da região chega a 2 anos) é necessário dar entrada nos Wórgãos o quanto antes, desta forma os projetistas tem pouco 
tempo para seu desenvolvimento. Isto também prejudica a qualidade, pois os projetos são desenvolvidos com pouco detalhamento. Para o sistema de lajes pré-fabricadas a falta de precisão no projeto também foi impactante, a construção civil está acostumada a trabalhar com centímetros, mas para este sistema foi necessária precisão de milímetros.

A forma como é feita a tributação, o tempo elevado de aprovação e licenciamento, a falta de incentivos por consumir menos madeira e consequentemente gerar menos resíduos, por exemplo, dificultou a viabilização do processo. $O$ apoio e incentivo de órgãos governamentais pode ser um fator decisivo para utilização de sistemas industrializados.

\section{CONSIDERAÇÕES FINAIS}

A utilização de pré-fabricados (uma etapa para a industrialização) na construtora, permitiu que os trabalhadores que antes estavam sujeitos às condições climáticas pudessem trabalhar em ambiente protegido. Também diminuiu o trabalho pesado, pois a fábrica e a obra puderam dispor de equipamentos adequados de içamento e transporte.

Em relação aos dados apresentados na Figura 9 e no restante da pesquisa, não é possível concluir o motivo da diferença de consumo de madeira nas áreas comuns, instalações de segurança, instalações provisórias e fundações, por dependerem de outros fatores como projeto arquitetônico, terreno e tipo de solo, por exemplo.

No pavimento térreo e ático houve uma redução no consumo de madeira de $61 \%$, como o layout é o mesmo nos dois projetos e o aumento de área do empreendimento $\mathrm{F}$ já foi considerado nos cálculos, pode-se concluir que a utilização de um sistema misto trouxe vantagens. Já no pavimento tipo a pré-fabricação eliminou totalmente a utilização de madeira no empreendimento $G$.

De forma simplificada, a utilização parcial dapré-fabricação trouxe uma redução de $25 \%$ no consumo de madeira. Reduzindo consequentemente os resíduos de obra. Toda a madeira que era utilizada em formas eescoramento ia para descarte, pois já não era mais reutilizável ao fim da obra. Muitas pesquisas falam em reciclagem e reutilização como forma de tornar a construção civil mais sustentável, mas se for possível nem gerar estes resíduos o impacto para o meio ambiente será ainda menor.

Outro ponto discutível é a utilização de madeira certificada, a construtora utiliza apenas este tipo de matéria prima (uma exigência das certificações) e também faz a destinação correta de todos os resíduos. Porém os dados do Serviço Florestal Brasileiro, apresentados na Figura 1, mostram que a quantidade de vegetação nativa tem diminuído. Ainda que a quantidade de florestas plantadas tenha aumentado, o fato de não serem vegetações naturais do ecossistema prejudica a fauna e flora locais. Desta forma a utilização de pré-fabricados colabora pela eliminação completa da necessidade de madeira.

Um ponto visto como negativo em relação à sustentabilidade é a flexibilidade de projeto, por ser em alvenaria estrutural e com lajes pré-fabricadas a planta não permite alterações, podendo não se adequar as novas necessidades.

A sustentabilidade vem tomando proporções cada vez maiores e se tornando um tema cada vez mais abrangente. A busca por uma construção mais sustentável tem gerado debates e muitas vezes visões divergentes de uma mesma questão. Qualquer alteração feita no ambiente natural já parte do princípio de não ser sustentável, por isso a busca por soluções que gerem menos impactos deve seguir os princípios de uma melhoria contínua.

\section{REFERÊNCIAS}

ARAÚJO, M. A. A moderna construção sustentável. 2008. Disponível em: \&lt;https://www.aecweb.com. br/cont/a/a-moderna-construcao- sustentavel_589\&gt; Acesso em: 18 jan. 2018.

BEZERRA, M. de M.; OLIVEIRA, A. J. de. Qualiverde: histórico, projetos e próximos passos. Mix Sustentável, Florianópolis, v. 2, n. 2, p.80-86, abr. 2016. Semestral.

BRUNA, P. J. V. Arquitetura, industrialização e desenvolvimento. 2. ed. São Paulo: Perspectiva, 2013. 307 p.

BRUNDTLAND, G. H. et al. Nosso futuro comum: relatório de Brundtland. Rio de Janeiro: FGV, 1987.

CARVALHO, M. T. M. Metodologia para avaliação da sustentabilidade de habitações de interesse social com foco no projeto. 2009. 223 f. Tese (Doutorado) - Curso de Faculdade de Tecnologia, Engenharia Civil e Ambiental, Unb, Brasília, 2009. Disponível em: \&lt;http:// www.pecc.unb.br/wp-content/uploads/teses/D09-3AMichele-Carvalho.pdf\&gt;. Acesso em: 18 jan. 2018.

CIB \&amp; UNEP-IETC. Agenda 21 for sustainable construction in developing countries: a discussion document. 2002. Disponível em: \&lt;http://www.unep.or.jp/ietc/ Focus/Agenda 21BOOK.pdf\&gt;. Acesso em: 18 jan. 2018.

FRANCO, Luiz Sérgio. Aplicação de diretrizes de racionalização construtiva para a evolução tecnológica dos processos construtivos em alvenaria 
estrutural não armada. 1992. 319 f. Tese (Doutorado) Curso de Engenharia Civil, Departamento de Engenharia de Construção Civil, Escola Politécnica da Universidade de São Paulo, São Paulo, 1992.

LAMBERTS, R. et al. Sustentabilidade nas edificações: contexto internacional e algumas referências brasileiras na área. 2007. Disponível em: \&lt;http://www.labeee.ufsc.br/ sites/default/files/documents/sustentabilidade_nas_edificacoes_contexto_internacional_e_algumas_referencias_brasileiras_na_areasustentabilidade_nas_edificacoes_contexto_internacional_e_algumas_referencias_brasileiras_na_area.pdf\&gt;. Acesso em: 18 jan. 2018.

PRIZIBELA, S. C. C.; OLIVEIRA, R. de. Aplicação de princípios de sustentabilidade em empreendimentos de grande porte: posicionamento dos arquitetos. Mix Sustentável, Florianópolis, v. 2, n. 1, p.90-97, abr. 2016. Semestral.

RUTHES, T. Impactos do desenvolvimento de um processo construtivo industrializado em alvenaria estrutural. 2016. 195 f. Dissertação (Mestrado) - Curso de Programa de Pós-graduação em Engenharia Civil, Centro Tecnológico, UFSC, Florianópolis, 2016.

SATTLER, M. A.. Entrevista. Mix Sustentável, Florianópolis, v. 3, n. 1, p.124-131, mar. 2017. Semestral.

SBF. Serviço Florestal Brasileiro (Brasil). Florestas do Brasil: em resumo. 2009. Disponível em: \&lt;http://www. florestal.gov.br/documentos/publicacoes/1805-florestasdo-brasil- em-resumo-2009/file\&gt;. Acesso em: 18 jan. 2018.

SBF. Serviço Florestal Brasileiro (Brasil). Florestas do Brasil: em resumo. 2010. Disponível em: \&lt;http://www. florestal.gov.br/documentos/publicacoes/1784-florestasdo-brasil- em-resumo-2010/file\&gt;. Acesso em: 18 jan. 2018.

SBF. Serviço Florestal Brasileiro (Brasil). Florestas do Brasil: em resumo. 2013. Disponível em: \&lt; http://www. florestal.gov.br/documentos/publicacoes/1797-florestasdo-brasil- em-resumo-2013-atualizado- em-novembro2013/file\&gt;. Acesso em: 18 jan. 2018.

SEVERINO, A. J. Metodologia do trabalho científico. 23. ed. São Paulo: Cortez, 2007. 304 p.

YIN, R. K. Estudo de caso: planejamento e métodos. 2. ed. Porto Alegre: Bookman, 2001. 203 p. 